\title{
Effects of $10 \%$ lidocaine spray on arterial pressure increase due to suspension laryngoscopy and cough during extubation
}

\author{
Deok Hee Lee, and Sang-Jin Park \\ Department of Anesthesiology and Pain Medicine, College of Medicine, Yeungnam University, Daegu, Korea
}

Background: It is well known that suspension laryngoscopy (SL) produces marked hemodynamic changes. Coughing during extubation sometimes causes adverse clinical problems. We investigated whether $10 \%$ lidocaine spray could attenuate hemodynamic stress responses due to SL and reduce coughing incidence during extubation.

Methods: Sixty patients undergoing SL were randomly divided into two groups and intubated without 10\% lidocaine spray (control group) or given $1.5 \mathrm{mg} / \mathrm{kg}$ of $10 \%$ lidocaine, sprayed onto laryngeal and intratracheal sites 2 min prior to intubation (10\% lidocaine group). Mean arterial pressure (MAP) and heart rates (HR) during SL and coughing incidence during extubation were recorded.

Results: MAP at 2.5 and $5 \mathrm{~min}(\mathrm{P}<0.05)$ and $\mathrm{HR}$ at $2.5 \mathrm{~min}$ after SL $(\mathrm{P}<0.01)$ were greater in the control group than in the $10 \%$ lidocaine group. The number of coughs decreased in the $10 \%$ lidocaine group compared to the control group during pre- $(6.8 \pm 3.2 \mathrm{vs} 10.3 \pm 4.4, \mathrm{P}<0.01)$ and post-extubation period of $5 \min (4.0 \pm 2.3 \mathrm{vs} 6.2 \pm 4.2, \mathrm{P}<0.05)$ and during the entire study period $(10.8 \pm 3.9$ vs $16.5 \pm 5.6, \mathrm{P}<0.001)$.

Conclusions: Preoperative laryngeal and intratracheal spraying with $1.5 \mathrm{mg} / \mathrm{kg}$ of $10 \%$ lidocaine spray is effective for attenuation of arterial pressure increase to SL and suppression of coughing during extubation. (Korean J Anesthesiol 2011; 60: 422-427)

Key Words: Cough, Laryngoscopy, Lidocaine, Pressure.

Received: July 27, 2010. Revised: 1st, November 30, 2010; 2nd, December 8, 2010. Accepted: December 10, 2010.

Corresponding author: Deok Hee Lee, M.D., Ph.D., Department of Anesthesiology and Pain Medicine, College of Medicine, Yeungnam University, 317-1, Daemyung-dong, Nam-gu, Daegu 705-717, Korea. Tel: 82-53-620-3365, Fax: 82-53-626-5275, E-mail: dhlee415@ynu.ac.kr This research was supported by the Yeungnam University research grants in 2009.

(c) This is an open-access article distributed under the terms of the Creative Commons Attribution Non-Commercial License (http:// creativecommons.org/licenses/by-nc/3.0/), which permits unrestricted non-commercial use, distribution, and reproduction in any medium, provided the original work is properly cited. 


\section{Introduction}

Suspension laryngoscopy during laryngeal microscopic surgery for diagnosis or treatment of upper airway disorders may directly produce pressure stimulation on the laryngeal tissue. This causes marked cardiovascular responses via irritation of the deep sensory receptors of the larynx [1,2]. An increase of arterial pressure and heart rate caused by suspension laryngoscopy are usually temporary and rarely accompanied by sequelae [3]. Nevertheless, constant intraoperative vigilance is necessary because such increases can be fatal in patients who have hypertension, myocardial ischemia or cerebrovascular disease.

Coughing due to airway irritation during extubation can cause harmful effects such as hypertension, tachycardia, arrhythmia, myocardial ischemia, bronchospasm, bleeding at operative site, intracranial and intraocular hypertension $[4,5]$. Moreover, the likelihood of postoperative coughing can increase in laryngeal microscopic surgery in which the stimulus of surgical and suspension laryngeal manipulation is largely concentrated on the larynx or vocal cord.

Lidocaine administered to the larynx or trachea is known to be effective in suppressing blood pressure increase caused by intubation [6,7] and is also known for blocking cardiovascular responses to airway irritation $[8,9]$. We therefore hypothesized that $10 \%$ lidocaine spray may be helpful in attenuating the irritation caused by suspension laryngoscopy and extubation. In this study, we investigated the effects of preoperative $10 \%$ lidocaine spray on hemodynamic changes and coughing responses during suspension laryngoscopy and extubation under general anesthesia.

\section{Materials and Methods}

After obtaining institutional review board approval and informed consent from patients, 60 American Society of Anesthesiologists physical status I patients between the ages of 20-65 scheduled for laryngeal microscopic surgery with suspension laryngoscopy were included in this study.

Patients with the following conditions were excluded from the study: cardiovascular diseases, hypertension, diabetes mellitus, respiratory disease, recent history of respiratory infection, a known hypersensitivity to lidocaine, Cormack \& Lehane Class 3 or 4 , patients who were expected to have difficult intubation or patients who received antihypertensive drug due to an exaggerated hypertensive response during surgery.

Patients were randomly divided into a control group $(\mathrm{n}=30)$ and a $10 \%$ lidocaine group $(n=30)$. In both groups, patients were premedicated with glycopyrrolate $0.2 \mathrm{mg}$ intramuscularly $1 \mathrm{hr}$ before surgery. Pentothal sodium $4 \mathrm{mg} / \mathrm{kg}$ and alfentanil
$15 \mu \mathrm{g} / \mathrm{kg}$ were intravenously administered for anesthetic induction. In case of adequate ventilation, rocuronium bromide $0.6 \mathrm{mg} / \mathrm{kg}$ was administered as muscle relaxants. Two min after the administration of muscle relaxants, patients from the control group were intubated with no treatment, whereas for patients in the $10 \%$ lidocaine group, after checking the Cormack \& Lehane Classification under direct vision with a Macintosh laryngoscope, the trachea was sprayed using $1.5 \mathrm{mg} / \mathrm{kg}$ of $10 \%$ lidocaine spray (Xylocaine 10\% spray, AstraZeneca, Korea). Fifty percent of total dose was sprayed on the larynx and epiglottic area and the other $50 \%$ in the trachea. This was followed by immediate endotracheal intubation. During the anesthesia, standard monitoring devices (Multi Channel Anesthesia Monitor S/5, Datex-ohmeda, Beaverton, Oregon, USA) were applied to measure electrocardiography, noninvasive blood pressure, heart rate, pulse oximetry, capnography, and endtidal sevoflurane concentration. Anesthesia was maintained with $2.0 \%$ end-tidal sevoflurane and $\mathrm{O}_{2} / \mathrm{N}_{2} \mathrm{O}$ 1.5/1.5 L/min. Using a bispectral index (BIS) monitor (A-2000 BIS ${ }^{\circledR}$ Monitor System; Aspect Medical Systems, Newton, Messachusetts, USA) BIS values were maintained by $40-60$ by adjusting 0.5 vol\% of sevoflurane each time. Ventilation of the lungs was adjusted to maintain an end-tidal carbon dioxide of $30-35 \mathrm{mmHg}$.

Upon arriving at the operating room, before anesthetic induction, arterial blood pressure and heart rate were measured at a stable state as baseline values. After intubation, suspension laryngoscopy was undertaken in both groups after waiting until arterial blood pressures and heart rates returned to the baseline values. Arterial blood pressures and heart rates were measured immediately before suspension laryngoscopy, at $2.5 \mathrm{~min}, 5$ min and $10 \mathrm{~min}$ after suspension laryngoscopy. Sevoflurane and $\mathrm{N}_{2} \mathrm{O}$ administration were immediately discontinued after withdrawal of suspension laryngoscopy, and subjects were then ventilated with $100 \% \mathrm{O}_{2}$ at $5 \mathrm{~L} / \mathrm{min}$. Glycopyrrolate and pyridostigmine were administered intravenously to reverse muscle relaxation if the TOF responses $>2$. At 5 min after reversing muscle relaxation, tracheal tubes were removed when the TOF ratio $(\mathrm{T} 4 / \mathrm{T} 1)$ was $>0.7$. If TOF ratio was $<0.7$, extubation was delayed and the patient was excluded from study. Number of coughs and rating of coughing per patient from $5 \mathrm{~min}$ before extubation to immediately before extubation and from immediately after extubation to 5 min after extubation were recorded. Arterial blood pressures and heart rates were measured 5 min before extubation, 2.5 min before extubation, immediately before extubation, immediately after extubation, at $2.5 \mathrm{~min}$ and $5 \mathrm{~min}$ after extubation. All data were recorded by an anesthesiologist unaware of study protocol and patient groups. Side effects were investigated the day after surgery.

Statistical analysis was performed using SPSS ${ }^{\circledR}$ 17.0. software (SPSS Inc., Chicago, IL, USA). Between the groups, the demo- 
graphic data, arterial blood pressure, heart rate and number of coughs were analyzed using an unpaired t test. Arterial blood pressures and heart rates of each group were analyzed using repeated measures of ANOVA. Nonparametric data were analyzed using chi-square test and Fisher's exact test. $\mathrm{P}<0.05$ was considered significant.

\section{Results}

Five patients were excluded from the analysis because of Cormack \& Lehane Class 3 or 4 (one in the control group and one in the $10 \%$ lidocaine group), because of administration of antihypertensive drugs due to an exaggerated hypertensive response during surgery (two in the control group) or because the TOF ratio was $<0.75$ min after reversing muscle relaxation (one in the $10 \%$ lidocaine group).

No statistically significant differences were found between the two study groups with respect to demographic data, time of operation and anesthesia, or number of smokers (Table 1).

As compared with baseline values, mean arterial pressure (MAP) and heart rates increased $2.5 \mathrm{~min}$ and $5 \mathrm{~min}$ after suspension laryngoscopy $(\mathrm{P}<0.05)$, and no significant difference was observed at $10 \mathrm{~min}$ after suspension laryngoscopy in the two groups. However, MAP at 2.5 and 5 min after suspension laryngoscopy $(\mathrm{P}<0.05)$ and heart rates $2.5 \mathrm{~min}$ after suspension laryngoscopy $(\mathrm{P}<0.01)$ in the control group were significantly

Table 1. Characteristics of Patients

\begin{tabular}{lcc}
\hline & $\begin{array}{c}\text { Control group } \\
(\mathrm{n}=27)\end{array}$ & $\begin{array}{c}10 \% \text { lidocaine group } \\
(\mathrm{n}=28)\end{array}$ \\
\hline Age (yr) & $53.7 \pm 5.9$ & $56.1 \pm 4.5$ \\
Sex (M/F) & $18 / 9$ & $16 / 12$ \\
Height (cm) & $162.1 \pm 4.7$ & $160.5 \pm 6.8$ \\
Weight (kg) & $64.2 \pm 7.8$ & $63.4 \pm 8.0$ \\
Operating time (min) & $13.5 \pm 6.5$ & $14.1 \pm 8.4$ \\
Anesthesia time (min) & $28.9 \pm 7.2$ & $30.1 \pm 7.9$ \\
Number of smoker & 10 & 8 \\
\hline
\end{tabular}

Values were expressed as mean \pm SD or number. higher than in the $10 \%$ lidocaine group (Table 2).

Number of coughs for 5 min before extubation $(\mathrm{P}<0.01)$, for 5 min after extubation $(\mathrm{P}<0.05)$, and during the entire study period $(\mathrm{P}<0.001)$ in the $10 \%$ lidocaine group were lower than in the control group (Table 3 ).

MAP at 2.5 min before extubation $(\mathrm{P}<0.05)$, immediately before extubation $(\mathrm{P}<0.001)$, and immediately after extubation $(\mathrm{P}<0.05)$ in the control group were significantly higher than in the $10 \%$ lidocaine group. Heart rate in the control group was higher than in the $10 \%$ lidocaine group $2.5 \mathrm{~min}$ before extubation $(\mathrm{P}<0.05)$, immediately before extubation $(\mathrm{P}<0.01)$, and 2.5 min after extubation $(\mathrm{P}<0.05)$. As compared with 5 min before extubation, MAP increased from 2.5 min before extubation to $2.5 \mathrm{~min}$ after extubation $(\mathrm{P}<0.001)$ in the control group, and increased from $2.5 \mathrm{~min}$ before extubation to $2.5 \mathrm{~min}$ after extubation $(\mathrm{P}<0.001)$ and at 5 min after extubation $(\mathrm{P}<$ 0.01 ) in the $10 \%$ lidocaine group. In both groups, heart rates from 2.5 min before extubation to $2.5 \mathrm{~min}$ after extubation $(\mathrm{P}<$ 0.05) higher than 5 min before extubation (Table 4).

There were 5 patients with sorethroat and 2 patients with swallowing difficulty in the control group, and 6 patients with sorethroat and 2 patients with swallowing difficulty in the $10 \%$

Table 3. Number of Coughs and Incidence of Coughing during Extubation

\begin{tabular}{|c|c|c|}
\hline & $\begin{array}{l}\text { Control group } \\
\quad(\mathrm{n}=27)\end{array}$ & $\begin{array}{l}10 \% \text { lidocaine } \\
\text { group }(\mathrm{n}=28)\end{array}$ \\
\hline \multicolumn{3}{|l|}{ I. Pre-extubation period of $5 \mathrm{~min}$} \\
\hline Number of coughs & $10.3 \pm 4.4$ & $6.8 \pm 3.2^{\dagger}$ \\
\hline Incidence of coughing (\%) & $27 / 27(100)$ & $23 / 28(82.1)$ \\
\hline \multicolumn{3}{|l|}{ II. Post-extubation period of $5 \mathrm{~min}$} \\
\hline Number of coughs & $6.2 \pm 4.2$ & $4.0 \pm 2.3^{*}$ \\
\hline Incidence of coughing $(\%)^{\S}$ & $25 / 27(92.6)$ & $19 / 28(67.9)$ \\
\hline \multicolumn{3}{|l|}{ III. Period of I + II } \\
\hline Number of coughs & $16.5 \pm 5.6$ & $10.8 \pm 3.9^{\ddagger}$ \\
\hline Incidence of coughing (\%) & $27 / 27(100)$ & $23 / 28(82.1)$ \\
\hline
\end{tabular}

Values were expressed as mean $\pm \mathrm{SD}$ or number. $* \mathrm{P}<0.05,{ }^{\dagger} \mathrm{P}<0.01$ ${ }^{\ddagger} \mathrm{P}<0.001$ as compared with the control group. ${ }^{\S} \mathrm{P}<0.05$ between the control and $10 \%$ lidocaine groups.

Table 2. Mean Arterial Pressures and Heart Rates during Application of Suspension Laryngoscope

\begin{tabular}{|c|c|c|c|c|c|}
\hline & $\mathrm{T} 1$ & $\mathrm{~T} 2$ & T3 & $\mathrm{T} 4$ & T5 \\
\hline \multicolumn{6}{|l|}{ MAP (mmHg) } \\
\hline Control group & $88.9 \pm 2.9$ & $92.1 \pm 11.6$ & $117.7 \pm 16.9^{\|}$ & $109.8 \pm 10.1^{\|}$ & $95.8 \pm 10.2$ \\
\hline $10 \%$ lidocaine group & $89.2 \pm 3.1$ & $88.8 \pm 8.9$ & $105.7 \pm 15.6^{*, \|}$ & $100.9 \pm 15.1^{*, \S}$ & $89.5 \pm 6.7$ \\
\hline \multicolumn{6}{|l|}{ HR (beats/min) } \\
\hline Control group & $76.6 \pm 10.3$ & $84.4 \pm 13.9$ & $105.3 \pm 16.7^{\|}$ & $90.1 \pm 13.1^{\S}$ & $77.6 \pm 10.5$ \\
\hline $10 \%$ lidocaine group & $75.5 \pm 7.4$ & $78.0 \pm 14.0$ & $91.0 \pm 16.4^{\dagger, \|}$ & $83.4 \pm 15.2^{\ddagger}$ & $81.3 \pm 14.9$ \\
\hline
\end{tabular}

Values were expressed as mean \pm SD. T1: pre-induction, T2: pre-application of suspension laryngoscope, T3: 2.5 min after suspension laryngoscope, T4: 5 min after suspension laryngoscope, T5: 10 min after suspension laryngoscope, MAP: mean arterial pressure, HR: heart rate. ${ }^{*} \mathrm{P}<0.05,{ }^{\dagger} \mathrm{P}<0.01$ as compared with the control group and ${ }^{\dagger} \mathrm{P}<0.05,{ }^{\S} \mathrm{P}<0.01,{ }^{1 "} \mathrm{P}<0.001$ as compared with pre-induction. 
Table 4. Mean Arterial Pressures and Heart Rates during Extubation

\begin{tabular}{|c|c|c|c|c|c|c|}
\hline & $\mathrm{T} 1$ & $\mathrm{~T} 2$ & T3 & $\mathrm{T} 4$ & T5 & T6 \\
\hline \multicolumn{7}{|l|}{ MAP (mmHg) } \\
\hline Control group & $101.5 \pm 9.5$ & $114.7 \pm 10.2^{q}$ & $117.3 \pm 8.2^{\llbracket}$ & $118.2 \pm 9.4^{\pi}$ & $111.0 \pm 7.7^{ף}$ & $106.8 \pm 9.6$ \\
\hline $10 \%$ lidocaine group & $96.8 \pm 11.5$ & $107.9 \pm 11.7^{*, \pi}$ & $108.8 \pm 7.3^{\text {†, }}$ & $111.6 \pm 11.4^{*, \uparrow}$ & $106.9 \pm 10.0$ & $102.7 \pm 8.5^{\prime \prime}$ \\
\hline \multicolumn{7}{|l|}{ HR (beats/min) } \\
\hline Control group & $90.3 \pm 15.0$ & $105.3 \pm 19.4^{\pi}$ & $108.9 \pm 16.8^{\pi}$ & $103.8 \pm 14.4^{\|}$ & $100.4 \pm 14.9^{\S}$ & $94.9 \pm 14.0$ \\
\hline $10 \%$ lidocaine group & $83.6 \pm 15.8$ & $91.4 \pm 16.4^{* \pi}$ & $91.1 \pm 18.7^{\dagger, \|}$ & $96.0 \pm 14.1^{\pi}$ & $90.3 \pm 15.4^{*, \S}$ & $88.0 \pm 15.9$ \\
\hline
\end{tabular}

Values were expressed as mean \pm SD. T1: 5 min before extubation, T2: 2.5 min before extubation, T3: immediately before extubation, T4: immediately after extubation, T5: 2.5 min after extubation, T6: 5 min after extubation, MAP: mean arterial pressure, HR: heart rate. *P < 0.05, ${ }^{\dagger} \mathrm{P}<0.01,{ }^{\ddagger} \mathrm{P}<0.001$ as compared with the control group and ${ }^{\S} \mathrm{P}<0.05,{ }^{\text {"}} \mathrm{P}<0.01,{ }^{\mathrm{T}} \mathrm{P}<0.001$ as compared with $\mathrm{T} 1$.

Table 5. Comparison of Postoperative Complications

\begin{tabular}{lcc}
\hline & $\begin{array}{c}\text { Control group } \\
(\mathrm{n}=27)\end{array}$ & $\begin{array}{c}\text { 10\% lidocaine group } \\
(\mathrm{n}=28)\end{array}$ \\
\hline Sorethroat & 5 & 6 \\
Swallowing difficulty & 2 & 2 \\
Aspiration & 0 & 0 \\
Laryngospasm or & 0 & 0 \\
bronchospasm & & \\
\hline
\end{tabular}

Values were expressed as number.

lidocaine group. However, no significant inter-group difference was observed and no patient in either group was serious enough to require treatment (Table 5).

\section{Discussion}

In the present study, 10\% lidocaine sprayed on laryngeal and intratracheal site suppressed elevation of arterial blood pressure and heart rate caused by suspension laryngoscopy and also reduced occurrence of coughing caused by airway irritation during extubation.

Airway irritation due to suspension laryngoscopy, in addition to surgical stimulation, accentuates the sympathetic nervous system and causes excessive elevation of arterial blood pressure and heart rate in laryngeal microscopic surgery. This can lead to complications, such as myocardial ischemia, myocardial infarction, and arrhythmia [1]. In one previous study, laryngeal microscopic surgery using suspension laryngoscopy had a higher rate of postoperative cardiac complications compared to other types of surgeries [3]. Thus, serious consideration by anesthesiologist should be given to the perioperative cardiovascular responses such as hypertension and tachycardia owing to suspension laryngoscopy. Opioids [10], $\alpha$ - and $\beta$-blockers [11], $\beta$-blockers [11] or $\alpha_{2}$ agonists [12] have been used, but these drugs should be used with care because of delays in postoperative awakening and occurrence of complications in decline of cardiac function. Time interval from spray to airway stimulation is important for lidocaine spray to be effective in reducing hemodynamic responses caused by airway irritation. Takita et al. [6] reported that studies regarding attenuation of noxious stimuli from endotracheal intubation at 2 min after lidocaine spray [13] and no attenuation within $1 \mathrm{~min}$ after lidocaine spray [14], indicate that 2 or more time intervals from lidocaine administration to airway stimulation are needed to reduce the hemodynamic responses due to endotracheal intubation. In this study, it seems that the lidocaine onset time against the suspension laryngoscopic stimulation was sufficient because it was sprayed before endotracheal intubation, and the suspension laryngoscopy was performed after waiting until the patients had stable hemodynamics from the intubation.

There have been several administration routes such as intravenous injection, endotracheal tube cuff or laryngotracheal instillation for lidocaine to prevent the occurrence of coughing caused from irritation during extubation. However, intravenous lidocaine injection during preextubation period may delay awakening from general anesthesia [15], and lidocaine administered into the endotracheal tube cuff can lead to a serious complication in case of rupture of cuff. Few studies have investigated the effects of $10 \%$ lidocaine spray on reducing postoperative coughing, although some studies have reported that laryngotracheal lidocaine administration was an effective way to prevent coughing [8,15-17]. Soltani and Aghadavoudi [18] compared postoperative coughing rates via various administration routes of lidocaine. They observed that $10 \%$ lidocaine spray not only had a higher coughing incidence than administration of lidocaine into the endotracheal tube cuff or intravenous lidocaine injection at the end of surgery, but also had no difference compare to the control group. In their research, however, the lidocaine doses for each group were not the same, and the lidocaine dose in the $10 \%$ lidocaine spray group was $30 \mathrm{mg}$. When $1.5 \mathrm{mg} / \mathrm{kg}$ of lidocaine was sprayed in this study, the number of coughs for 5 min before and after extubation, and the incidence of coughing during 5 min after extubation were significantly lower than in the control group. Also, the arterial blood pressures and heart rates in the $10 \%$ lidocaine group were sustained stably during the 
extubation period than in the control group. Therefore, these results indicate that the $10 \%$ lidocaine spray can adequately block the circulatory responses and airway stimuli due to the endotracheal tube.

The mechanism for attenuation of airway stimuli and hemodynamic responses by locally administered lidocaine such as spray into the laryngotracheal site may be interpreted as an increase in blood concentration due to systemic absorption of lidocaine, or a topical local anesthetic effect. In case of intravenously administered lidocaine, cough reflex owing to airway stimulation during tracheal intubation or emergence was suppressed by plasma lidocaine concentration in excess of 3 $\mu \mathrm{g} / \mathrm{ml}[19,20]$. However, plasma concentration of lidocaine administered in the trachea is generally lower than when administered intravenously $[4,21,22]$, and intratracheal spray of $2.0 \mathrm{mg} / \mathrm{kg}$ of lidocaine prevented hyperdynamic circulatory responses due to endotracheal intubation even in plasma concentration of $1.5 \mu \mathrm{g} / \mathrm{ml}$ [23]. The $1.5 \mathrm{mg} / \mathrm{kg}$ of lidocaine sprayed in the present study is considered inadequate to reach $3 \mu \mathrm{g} / \mathrm{ml}$ of plasma concentration. Accordingly, no increase in plasma concentration by systemic absorption of lidocaine but by topical local anesthetic effect is believed to suppress circulatory responses and coughing due to airway stimulation.

Problems such as the occurrence of postoperative sorethroat should also be considered, although lidocaine spray before endotracheal intubation can be a useful method to attenuate airway irritation due to endotracheal tubes. With respect to postoperative sorethroat occurring due to lidocaine spray, there have been conflicting results in previous reports. Maruyama et al. [24] reported that when $\mathbf{8 \%}$ lidocaine is sprayed before intubation, additives such as 1-menthol, ethanol, and alkalized solvents contained in lidocaine spray might add to the damage on the tracheal mucosa, thus leading to an increase in the incidence of postoperative sorethroat after total intravenous anesthesia. However, Herlevsen et al. [25] showed that there was no significant correlation between lidocaine spray and incidence of postoperative sorethroat. Klemola et al. [26] also reported that lidocaine spray itself did not play a significant role in the incidence of sorethroat, although the concomitant use of lidocaine spray and jelly increased postoperative sorethroat. Moreover, Oh et al. [27] reported that preoperative $10 \%$ lidocaine spray to pharyngolaryngeal and intratracheal sites reduces the incidence of postoperative sorethroat. In the present study, $10 \%$ lidocaine spray did not cause any serious postoperative complications, and in contrast to the report by Maruyama et al. [24], we were able to show that the incidence of postoperative sorethroat did not increase from the use of lidocaine spray.

In summary, we investigated the ability of $10 \%$ lidocaine spray to attenuate stimuli due to suspension laryngoscopy or extubation in patients undergoing laryngeal microscopic surgery with suspension laryngoscope. Our results show that 1.5 $\mathrm{mg} / \mathrm{kg}$ of $10 \%$ lidocaine preoperatively sprayed on laryngeal and intratracheal site not only effectively blocked cardiovascular responses due to suspension laryngoscopy but also suppressed coughing that follows extubation. These findings indicate that preoperative $10 \%$ lidocaine spray may be helpful in maintaining stable hemodynamics in laryngeal microscopic surgery with suspension laryngoscope.

\section{References}

1. Wenig BL, Raphael N, Stern JR, Shikowitz MJ, Abramson AL. Cardiac complications of suspension laryngoscopy. Fact or fiction? Arch Otolaryngol Head Neck Surg 1986; 112: 860-2.

2. Mustola ST, Baer GA, Metsä-Ketelä T, Laippala P. Haemodynamic and plasma catecholamine responses during total intravenous anaesthesia for laryngomicroscopy. Thiopentone compared with propofol. Anaesthesia 1995; 50: 108-13.

3. Strong MS, Vaughan CW, Mahler DL, Jaffe DR, Sullivan RC. Cardiac complications of microsurgery of the larynx: etiology, incidence and prevention. Laryngoscope 1974; 84: 908-20.

4. Bidwai AV, Bidwai VA, Rogers CR, Stanley TH. Blood-pressure and pulse-rate responses to endotracheal extubation with and without prior injection of lidocaine. Anesthesiology 1979; 51: 171-3.

5. Leech P, Barker J, Fitch W. Proceedings: Changes in intracranial pressure and systemic arterial pressure during the termination of anaesthesia. Br J Anaesth 1974; 46: 315-6.

6. Takita K, Morimoto Y, Kemmotsu O. Tracheal lidocaine attenuates the cardiovascular response to endotracheal intubation. Can J Anaesth 2001; 48: 732-6.

7. Park YO, Bang KS, Choi EM, Hong SJ, Kim IS, Shin KM, et al. Plasma Lidocaine Concentration and Hemodynamic Effect after 10\% Lidocaine Spray on Laryngopharyngeal and Intratracheal Site during the Endotracheal Intubation. Korean J Anesthesiol 2005; 49: 152-6.

8. Minogue SC, Ralph J, Lampa MJ. Laryngotracheal topicalization with lidocaine before intubation decreases the incidence of coughing on emergence from general anesthesia. Anesth Analg 2004; 99: 1253-7.

9. Hamaya Y, Dohi S. Differences in cardiovascular response to airway stimulation at different sites and blockade of the responses by lidocaine. Anesthesiology 2000; 93: 95-103.

10. Pandazi AK, Louizos AA, Davilis DJ, Stivaktakis JM, Georgiou LG. Inhalational anesthetic technique in microlaryngeal surgery: a comparison between sevoflurane-remifentanil and sevofluranealfentanil anesthesia. Ann Otol Rhinol Laryngol 2003; 112: 373-8.

11. Ayuso A, Luis M, Sala X, Sánchez J, Traserra J. Effects of anesthetic technique on the hemodynamic response to microlaryngeal surgery. Ann Otol Rhinol Laryngol 1997; 106: 863-8.

12. Matot I, Sichel JY, Yofe V, Gozal Y. The effect of clonidine premedication on hemodynamic responses to microlaryngoscopy and rigid bronchoscopy. Anesth Analg 2000; 91: 828-33.

13. Denlinger JK, Ellison N, Ominsky AJ. Effects of intratracheal lidocaine on circulatory responses to tracheal intubation. 
Anesthesiology 1974; 41: 409-12.

14. Hamill JF, Bedford RF, Weaver DC, Colohan AR. Lidocaine before endotracheal intubation: intravenous or laryngotracheal? Anesthesiology 1981; 55: 578-81.

15. Gonzalez RM, Bjerke RJ, Drobycki T, Stapelfeldt WH, Green JM, Janowitz MJ, et al. Prevention of endotracheal tube-induced coughing during emergence from general anesthesia. Anesth Analg 1994; 79: 792-5.

16. Diachun CA, Tunink BP, Brock-Utne JG. Suppression of cough during emergence from general anesthesia: laryngotracheal lidocaine through a modified endotracheal tube. J Clin Anesth 2001; 13: 447-51.

17. Jee D, Park SY. Lidocaine sprayed down the endotracheal tube attenuates the airway-circulatory reflexes by local anesthesia during emergence and extubation. Anesth Analg 2003; 96: 293-7.

18. Soltani HA, Aghadavoudi O. The effect of different lidocaine application methods on postoperative cough and sore throat. J Clin Anesth 2002; 14: 15-8.

19. Yukioka H, Yoshimoto N, Nishimura K, Fujimori M. Intravenous lidocaine as a suppressant of coughing during tracheal intubation. Anesth Analg 1985; 64: 1189-92.

20. Nishino T, Hiraga K, Sugimori K. Effects of i.v. lignocaine on airway reflexes elicited by irritation of the tracheal mucosa in humans anaesthetized with enflurane. Br J Anaesth 1990; 64: 682-7.
21. Prengel AW, Lindner KH, Hähnel J, Ahnefeld FW. Endotracheal and endobronchial lidocaine administration: effects on plasma lidocaine concentration and blood gases. Crit Care Med 1991; 19: 911-5.

22. Groeben H, Silvanus MT, Beste M, Peters J. Both intravenous and inhaled lidocaine attenuate reflex bronchoconstriction but at different plasma concentrations. Am J Respir Crit Care Med 1999; 159: 530-5.

23. Yusa T, Taira Y, Sasara T, Yoza K. Effects of intratracheal lidocaine spray on circulatory responses to endotracheal intubation. Masui 1990; 39: 1325-32.

24. Maruyama K, Sakai H, Miyazawa H, Iijima K, Toda N, Kawahara $\mathrm{S}$, et al. Laryngotracheal application of lidocaine spray increases the incidence of postoperative sore throat after total intravenous anesthesia. J Anesth 2004; 18: 237-40.

25. Herlevsen P, Bredahl C, Hindsholm K, Kruhøffer PK. Prophylactic laryngo-tracheal aerosolized lidocaine against postoperative sore throat. Acta Anaesthesiol Scand 1992; 36: 505-7.

26. Klemola UM, Saarnivaara L, Yrjölä H. Post-operative sore throat: effect of lignocaine jelly and spray with endotracheal intubation. Eur J Anaesthesiol 1988; 5: 391-9.

27. Oh YJ, Kim HK, Park DH. The Effect of $10 \%$ Lidocaine Spray on Hemodynamics and Postoperative Sore Throat Accompanied by Endotracheal Intubation. Korean J Anesthesiol 1996; 30: 663-7. 